\title{
RE-EXAMINING POLITENESS, FACE AND THE JAPANESE LANGUAGE Barbara PIZZICONI*
}

\section{Introduction}

Among the many challenges received by Brown and Levinson's (1987) (B\&L henceforth) universally celebrated study on Politeness Universals, a particularly significant one is the critique of the notion of 'face', and hence of claims of universality in their model, proposed by two Japanese scholars. Ide's (1989) and Matsumoto's (1988, 1989, 1993) work has gained wide recognition and has become a standard reference for scholars in and outside Japan. The two researchers are considered promoters of a position that rejects B\&L's claim of the universality of 'face' and their attribution of a crucial role to polite strategies -as opposed to situation-triggered direct marking- in the communication of politeness. Their view could be defined as one that stresses the role of appropriateness over individual motivations as the prevalent regulating criterion in the speaker's manipulation of the utterance. Their line of work has gained relatively unquestioned acceptance by politeness theorists (Kasper, 1990; Janney and Arndt, 1993; Agha, 1994; Meier, 1995), as well as regular mention in works on Japanese and other languages (Nwoye, 1992; Ikeda 1993; Mao, 1994, de Kadt, 1998; Ji, 2000). To my current knowledge, only two works by Japanese scholars have appeared so far which question several aspects of Ide's and Matsumoto’s claims: Fukada and Asato (1997), and

\footnotetext{
*I wish to thank sincerely both my anonymous referees for providing invaluable comments, some of which I will no doubt reflect on for years to come, and one of them in particular for a most appropriate metalesson on politeness. I hope to have been able to translate at least some of their suggestions into improved lines of thought, the final quality of which I am of course solely responsible for. A big thank you also to Mark Jary who read an early draft.
} 
Usami (1997), whose research will be mentioned in this paper $^{1}$. In a passing mention of Japanese, Watts $(1992: 51,65,69)$ speculated that Japanese should be homologous to English with regards to the underlying mechanisms that regulate usage of honorific forms and verbal strategies (politeness as unmarked 'politic' behaviour ${ }^{2}$ ), but his line of argument does not seem to have been followed up in subsequent research on this language.

It is the claim of this paper that whilst evidence from Japanese ${ }^{3}$ (at least qualitatively speaking) seems to support the general criticism of B\&L with regards to the importance of ascribed vs. manipulative uses of politeness features (Fraser 1990, Meier 1995; Janney and Arndt 1992; Watts 1992), the very evidence presented by Ide and Matsumoto cannot be taken to support this criticism uncontroversially. This paper attempts to reassess this evidence, and to demonstrate that the principles regulating Japanese language are not inconsistent with B\&L's account of other languages, regarding the exploitation of pragmatic strategies to mitigate face threats and the two basic motivating factors for such mitigation: negative and positive aspects of face. Ide's and Matsumoto's observations may have prompted subsequent reflection on the notion of 'appropriateness' but their

\footnotetext{
${ }^{1}$ To this latter critical position belongs Pizziconi (1997) too, which provides the basis for this paper. The linguistic analyses presented here are reproduced more or less verbatim from (1997). However the literature reviewed and consequently the analysis proposed have been considerably amended in the present study.

${ }^{2}$ It is interesting to note that the notion of 'politic behaviour' corresponds rather neatly, being neutral to, or rather including, Politeness as well as Impoliteness, other-directed as well as self-directed behaviour, the Japanese general term for the study of interpersonal phenomena: Taiguu Hyoogen (lit. "Expressions of Treatment"). This was already in use in the late nineteenth century (Tsujimura 1992:132, 595), and the more frequently (but inappropriately) employed term: Keigo ("Linguistic Politeness") represents only the 'positive' subset of it (Shibata 1976:13).

${ }^{3}$ More precisely, the specific variety of Japanese discussed in this paper and arguably in all the other works referred to here, is the Tokyo-based standard variety.
} 
analysis does a disservice to the characterization of Japanese and to the larger discussion on cross-cultural correlates.

This paper also maintains that the principles regulating the Japanese language can be subsumed under a notion of a universal. A universal, to be precise, in the rather abstract sense expressed by Watts, of speakers' general communicative competence in interpreting context in order to derive, or satisfy, canons of 'appropriateness' (Watts 1992: 68; Meier, 1995:388). What makes Ide's and Matsumoto's claims unconvincing is precisely the assertion that these regulating principles are only locally valid, in other words the rejection of any notion of universality.

The critique of the Japanese critics of B\&L may suggest the author's alignment with the latter. This is true only in some respects, which will become clear during the discussion. In a nutshell, my position is that B\&L's unsurpassed articulation of politeness-related linguistic devices is undefeated by the Japanese scholar's analyses of Japanese linguistic devices. If differences or culture-specific facts are to be found, it will not be in the mechanics of the devices deployed to indicate the speakers' concern with the maintenance of both aspects of face. Rather, it will be in the specific content of face (what constitutes a loss, or a gain of face) and in the extent that this needs to be overtly attended to. In terms of the universality of positive and negative 'attitudes' to both aspects of face, Japanese speakers will be shown to have very similar concerns toward each other (and themselves).

On the other hand, I do subscribe to the more general criticism of B\&L, particularly with regards to their stress on inferential 'calculations' (which are held to be similar across languages) to the expense of fixed 'norms'. Their relative 'neglect' of the so-called ' $R$ ' factor (the specific ranking of the 'weight' of impositions in every one culture, B\&L 1987:76) is clearly a critical aspect of their model (for reasons that Hymes 1986: 76 explained very precisely). Additionally, their concentrating on the utterance level undermines the possibility of isolating culturally specific discourse patterns: different 
'combinations' of similar utterance-level devices (a point made again by Hymes 1986:78 and Agha 1994:284).

While criticizing the Japanese scholars, I also insist that many of their remarks have been absolutely crucial. For instance, the critique of the exaggerated role attributed to FTAs in a model of politeness, or the rejection of the pervasiveness of the negative strategies are utterly vital observations. It is indeed unfortunate that their papers have not proposed much consideration of, nor prompted further discussion on the role of positive politeness in human communication; the same could be said for the notion of selfdirected face-work. As more recent research (Bargiela, in press), and hopefully this paper demonstrate, these are necessary considerations in view of an urgently needed reconceptualization of politeness.

In order to explore these issues, I will proceed in this order: following a short reminder of the terms of the argument in $\mathrm{B} \& \mathrm{~L}$, I will first reconsider the linguistic analyses proposed by Matsumoto and Ide, cite evidence from other works on Japanese politeness, and suggest an alternative reading of the data. In 4., I will review the conclusions that can be drawn from this alternative analysis of Japanese, in relation to the parallel debate on possible future models of politeness.

\section{Brown and Levinson's model and Japanese politeness}

Before addressing Ide's and Matsumoto's criticism of B\&L, let us briefly remind ourselves of the crucial points of their model (see Glick 1996 for a recent reappraisal). Members of any community are thought to be concerned with a public self-image, which B\&L call face (1987:62). Face is construed as a want with a double nature: a want of freedom (freedom of action, and from imposition) - this is called the negative face, and a want of approval and appreciation - i.e. the positive face. Individuals are also endowed with the awareness that everybody else in the community is similarly concerned with 
face, and are able to act rationally and strategically (enact verbal strategies) so that this concern is more or less overtly attended to (64). Since human interaction inherently involves a certain degree of friction by its very nature (in other words, since every communicative act -e.g. asking something of, offering to, ordering, thanking, or even just addressing each other) impinges somehow on one's public face (65), individuals will try to redress these potential threats to face (Face Threatening Acts, or FTAs) by means of some ostensive strategy. Strategies can be ranked (68) from those involving greater risk of face loss (bold acts with no redressive measure) to those minimizing this loss (various degrees of redress up to a total avoidance of the threatening act).

For the purpose of the discussion presented in this paper it is important to note particularly the following points, summarised here but discussed in more detail in the following paragraphs.

B\&L's unrivalled description of linguistic devices involved in politeness crucially revolves around the rhetorical effects conveyed by syntactic and lexical devices which are not necessarily inherently 'honorific', but are nonetheless systematically used to express (and 'calculate') politeness. True honorifics significantly play a minor role in their paradigm. Additionally, their model presumes a deliberate or rational manipulation of these verbal strategies on the part of the individual for the purpose of facemaintenance. Both the notion of a deliberate exploitation of linguistic devices and the notion of a fundamentally atomistic ego are highly problematic for the Japanese scholars.

Ide's and Matsumoto's analyses share the aim of showing the inadequacy of B\&L's model by focusing, on the contrary, on the role of Japanese honorifics -a non-calculable type of polite device- which can convey face and politeness but are motivated by different speaker needs. These needs, submit the two Japanese scholars, do not correspond to internal factors such as the positive and negative aspects of an individual's face that B\&L proposed, but external factors such as mandatory social norms and a 
notion of an individual 'self' more embedded in social constraints than B\&L's Model Person.

\subsection{Matsumoto Yoshiko}

Matsumoto's critique of B\&L's framework hinges on two major points.

The first is a view of the self alternative to that posited by B\&L, in other words a different socio-cultural rationale: following a 'contextualist' paradigm, she rejects their very notion of the 'individual' and his needs as a unit of analysis. Japanese people, claims Matsumoto quoting sociological studies by Nakane, Doi and Sugiyama Lebra among others, do not prevalently perceive themselves as independent selves, but as members of networks and social structures. The basic need of such a social persona is not freedom of action, nor preservation of privacy, but creation of smooth, harmonious relations with the others, and development of interdependency. Hence, specifically on 'face', she argues that "the negative face want of preservation of individual territories seems alien to Japanese" (1988: 408)

On the linguistic level, she claims that the usage of Japanese politeness-related devices, which she calls 'relation-acknowledging-devices' (1988: $409 \mathrm{ff}$.), is more strongly constrained by the nature of social order and social stratification than by the need of redressing FTAs.

Supporting evidence for this claim are non-FTA utterances such as 'today is saturday' (1988: 415) that in Japanese can be expressed in (at least the following, colloquial) three ways. In this example, the copula's allomorph varies according to the relation between 
the speaker and the hearer, and not propositional content or illocutionary force, constant by definition, and non face-threatening ${ }^{4}$ :

1a. kyoo wa doyoobi da

1b. kyoo wa doyoobi desu

1c. kyoo wa doyoobi degozai masu

Consequently, in Japanese, the ability to give or obtain face by linguistics means allegedly depends on knowledge of social norms rather than skilful redress of FTAs.

Matsumoto elaborates on this point and discusses the greeting formula doozo yoroshiku onegai shimasu (lit.: <Please treat me favourably>, "Nice to meet you", see 2.1 below) as evidence that deference à la B\&L does not apply to Japanese. While in their model deference is related to rights to non-imposition, Matsumoto claims that this Japanese formula is actually rather polite despite its being an imposition. Hence "deference in Japanese [...] cannot be considered as deriving from the negative politeness strategy of minimizing the imposition on the addressee's action" (1988:409), and more explicitly, "Deference in Japanese culture focuses on the ranking difference between the conversational participants whereas Deference in Western culture is a strategy at least as likely to occur between equals."' (1988:424).

Since an FTA that conveys deference seriously contravenes B\&L's tenets (except perhaps for some particular cases treated as 'bald-on-record' strategies), this is a rather crucial point of Matsumoto's criticism, one which I will discuss in greater detail in section 2. Here, let us just record that for Matsumoto this formulaic expression symbolizes the prominence of one's relative position in society over one's individual

\footnotetext{
4 In order to maintain consistency across citations from sources that follow different conventions of transcription, I have occasionally modified the original and adopted the Hepburn system throughout the paper. I have followed however the Monbusho convention when transcribing "ou" as "oo".

${ }^{5}$ I use angle brackets for the <literal translation>, and quotation marks for the "conventional reading" of the utterance, whenever it seems relevant to pinpoint the difference between the two.
} 
needs: "what is important is the need to be judged as responding appropriately" (1988:412); likewise, the linguistic routines of gift-giving "illustrate maintenance of relative position as the prevailing dynamic in the Japanese politeness system" (p. 413); as for honorifics (as a closed set of direct social markers) "it is not negative politeness, the acknowledgement of the addressee's freedom from imposition that is conveyed by these forms, but a reflection of rank-ordering" (1988:414); giving/receiving verbs show that "the Japanese politeness system places a higher value on recognition of the interpersonal relation than on mitigating impositions on freedom of action" (1988:421).

Her subsequent study, Matsumoto (1989), discusses cases where it is not the addressee's status (as in the 'today is saturday' example), but the referent's status that triggers pragmatically obligatory choices at the lexical level, and with this she claims that systemic constraints (predominance of absolute rankings rather than illocutionary demands) are paramount in the selection of a honorific form. Just en passant, she notes that these lexical choices depend on both the referent position as well as on "the context of the utterance (including the relationship between speaker, addressee, bystanders and referent)" (1989:213), an observation which is in fact rather more significant than it looks, in view of the potential 'variability' it presupposes, as I will argue in section 3.

Unique characteristic of Japanese language are said to be the amount and type of modal information that a speaker is always, by default, forced to provide in utterances, and the pragmatic rules that govern that choice (1989:207).

Matsumoto $(1988: 419,1989: 219)$ noted the unsettling implication that every predicate in Japanese can be accompanied by different politeness-related markers, and therefore, if one subscribes to B\&L's definitions, one should envisage a potential FTA on every conceivable linguistic act, independently from propositional content and illocutionary force. This intuitively improbable hypothesis undermines B\&L's view of politeness as an FTA redressing device - if these markers are used also when no FTA is involved - or one must reformulate the notion of face to accommodate the speaker's obligation to simply be 
appropriate in order not to embarrass the audience and himself (which on the contrary can be posited as an underlying all-encompassing concern).

Matsumoto (1993) presents further examples from Japanese and discusses the inadequacy of a Gricean framework for an account of Japanese politeness.

\subsection{Ide Sachiko: the 'discernment' paradigm}

Ide (1989) finds B\&L's view of 'politeness as diplomatic behaviour' inadequate for a truly universal definition of politeness; she proposes that, in addition to the notion of 'intentional behaviour' oriented to facilitate favourable acceptance of one's message (or acts of 'Volition', major concern of B\&L) a definition of politeness should include the notion of 'conformity' to the "expected and/or prescribed norms of speech appropriate to the contextual situation in individual speech communities" (1989:225); in other words, a notion of politeness as 'etiquette', informed by the principle of 'Discernment' or wakimae (a notion subsumed under Fraser's (1990:21) social-norm based account of Politeness). This is "the choice of linguistic form or expression in which the distinction between the ranks or the roles of the speaker, the referent and the addressee are systematically encoded" (1989:230), hence linguistic behaviour oriented towards roles and situations, rather than face wants (1989:231).

Hill, Ide, Ikuta, Kawasaki and Ogino (1986), to which Ide refers us, specify that in "Discernment, the speaker can be considered to submit passively to the requirements of the/system" (1986:348). Interestingly, they claim universality for this principle, if "all human speakers use language according to politeness, which we believe is fundamentally determined by Discernment" (italic in the original, 1986:351); Discernment, and not Volition, is paramount because to "ignore its requirements brings social punishment"; violation of its rules "offends others and thus hurts the speakers' social image"; hence,

Discernment defines "one's minimal obligations within the polite-use sub-system. 
Volition, on the other hand, defines a range of permissible modifications to the former" (1986:351), therefore constituting, at best, only optional considerations.

The idea of a hierarchical ordering of the operating principles is unfortunately played down in this and the subsequent 1989 study; both Hill et al. (1986) and Ide (1989) prefer to elaborate on the Discernment/Volition continuum as a criterion for linguistic typology ${ }^{6}$. They note therefore "the relative prominence of Discernment over Volition in the polite use of language by speakers of Japanese. Conversely, Volition appears to predominate in the polite use of American English" (Hill et al. 1986:348); this is generalized by Ide (1989:231): "the more elaborated the linguistic system of formality, the greater the part the discernment aspect of language use plays in the language".

The two principles and their related linguistic devices are represented as follows (adapted from Ide 1989:232):

Discernment: Formal Forms, Pronouns, Address terms, Speech Levels, Speech Formulas

Volition: Verbal Strategies (Seek agreement, Joke, Question, Be pessimistic, etc.).

Typical honorifics of Japanese such as, for instance, the 'formal forms', have important characteristics: they are limited in number, but, more remarkably, they are grammatically and socio-pragmatically obligatory (and socio-pragmatic concord must be maintained). In other words, speakers of Japanese are forced to obligatory choices at the level of

${ }^{6}$ Significantly, Ide (1982), despite not making use of the terms 'discernment' and 'volition' yet, had come much closer to a universal, or at least very generalizable conceptualization of the notions by postulating 'formality' (the use of honorifics in a 'formal setting') as an 'overriding rule' over (the use of honorifics to express) 'politeness' (1982:371), which today could be reformulated as a primacy of discernment over volitional aspects. Ide (1982) also offers an extensive if perhaps not systematic description of interactional meanings generated by avoidance of honorifics (which I would define instances of 'volition'), or diverse functions that the use of honorifics can entail, such as (temporary) feelings of distance or intimacy, or "to protect ourselves from others" (1982: 376). All these observations on variation and multivalence are subsequently abandoned in favor of a more rigid juxtaposition of the two principles of Discernment and Volition. 
interpersonal modality encoded in honorifics. A simple utterance like: "I'll go/come": watashi-ga mairi-masu [humble $\mathrm{V}+$ formal suffix] (as opposed to watashi ga iki-masu [neutral V + formal suffix], or watashi ga iku [neutral V + casual suffix], my glosses) poses the problem of the linguistically and socio-pragmatically obligatory choice of (referent) honorifics, and the question of the level of appropriate formality (addressee honorifics), even in what seems to be a non-FTA act (1989:229).

\subsection{Preliminary observations}

The significance of the Japanese scholars' contribution is indisputable with regards to their highlighting one aspect of the Japanese honorifics' usage unaccounted for in B\&L's model, namely the usage of politeness-related interactional markers that operate independently from the presence of an FTA.

However, some of the conclusions drawn from this evidence seem unjustifiably overstated. Surely it is true, as Matsumoto points out, that "superficial similarity can result from different underlying principles" (1988:404), but that preservation of individual territories is a concept "alien" to Japanese people is proved wrong, for example, by what in Kamio's theory of the Territory of Information ${ }^{7}$ was later described

\footnotetext{
7 Kamio's 'ethological' approach to the notion of 'territory' proposes a framework for the study of evidentiality and politeness with an analysis of two languages: English and Japanese. His 'outbound strategy', that is related to B\&L's negative strategy, represents cases such as the following:

1 a. John's plan is not good b. I don't think John's plan is good

2 a. Kimi wa hashagi sugi da

b. Kimi, hashagi sugi ja nai no.

you TM overjoy-too is

You overjoy-too be not $\mathrm{CP}$

'You are too overjoyed'

Lit. 'May it not be that you are too overjoyed?'

in which the 'modest', hence potentially 'polite' effect is generated by the speaker's "intentionally talk[ing] as if he/she believed that the information fell outside his/her territory" (1997:189), i.e. by strategically 'distancing' him/herself from his/her natural ownership of the information. Note that in this case no
} 
as 'outbound strategies' - or cases where a polite implication is communicated via the speaker's increasing the distance between himself and (the ownership of) the information (Kamio, 1997:189). Systematic linguistic manipulation working via implications that the speaker is respecting the hearer's territory is observable in instances of Kabaya, et al.'s (1998) 'euphemistic expressions' ${ }^{8}$. Suzuki (1989:65) describes how negatively strategic considerations (such as the speaker's rights to impinge on the hearer's territory) constrain the use of desideratives, emotive/affective terms, the expression of the speaker's intentions or questions on the hearer's skills and abilities including usage of benefactive auxiliaries. Rhetorical usages such as hedging, questioning, apologizing (some of B\&L's typical negative strategies) are attested by Mimaki (1997). That Japanese too abides to a principle of respect of territory is an assumption at least authorized by Ide's own observation, that self-protection is just as much a motive for politeness as it is respect of others' status or age (1982:376). The applicability of B\&L's model person's needs to those of members of other cultural and linguistic communities has been questioned on an ontological basis (Janney and Arndt, 1993). However, given the linguistic evidence, the relevant question is not whether rights to non-imposition exist or not in Japanese, but rather what the exploitation of a notion of territory is aimed at in Japanese (if one rejects

honorific is used, and a relatively neutral syntactic structure does all the job. For a discussion of instances of positive politeness, that Kamio equates with ‘inbound strategies’ see 1997:190.

See also Suzuki 1989 for a further discussion of Japanese strategies within this framework.

${ }^{8}$ In Kabaya, Kawaguchi and Sakamoto's work on Japanese, ‘euphemistic expressions’ (atakamo hyougen) are a sort of semi-conventionalised indirect strategies; so a warning/advice can be systematically expressed as a (euphemistic) request, ("You should move away from the platform."> "Can you please move away from the platform?"), statements as (euphemistic) requests for permission ("I am going to leave now" > “May I leave now?”), etc. (1998:124 ff.). The category assignment of the 'underlying' expression is calculated on the basis of the three constitutive factors of 'actor', 'recipient of benefit' and 'party entitled to the decision', and 'polite' inferences are derived by the speaker's metaphorical manipulation of one of 
that it is aimed at protecting an individual's negative face), and in what circumstances it becomes necessary to employ it (what the scope of the territory is).

Reviews of Ide's and Matsumoto's work less uneasy with B\&L's claims of universality have struggled to provide alternative interpretations of the compelling evidence that Japanese simply does not work like English. In order to account for honorifics variation in utterances with the same propositional content, both Usami (1997:149) and Fukada (1997:5) resort to B\&L's calculation of the weight of an FTA $x$ $(\mathrm{W}=\mathrm{P}(\mathrm{S}, \mathrm{H})+\mathrm{D}(\mathrm{S}, \mathrm{H})+\mathrm{Rx})$, and submit that because when talking to superiors the value of $\mathrm{P}$ increases, the overall import of an act proportionally increases (variation is therefore a function of social factors and not propositional content). This legitimate observation when discussing FTAs, fails however to question why an utterance such as 'today is saturday' should be construed as an FTA at all; Fukada, who 'extends' the applicability of the formula to non-FTA acts, and talks generally of honorifics as 'mitigating' devices (and therefore must maintain that they embody a negative strategy, p. 5), is rather vague as to what is there to be 'mitigated'. In other words, both are rather unclear as to why respect or deference should be construed exclusively, or at least primarily, as a form of redress.

One notable problem we are faced with when assessing Ide's and Matsumoto's discussion is a certain casualness with the attribution of utterances to positive or negative strategies; this is not always an unequivocal, straightforward task, very much like the attribution of illocutionary force to an utterance ${ }^{9}$. An accurate analysis of honorifics usage, especially at discourse level (as well as the formulaic expression reanalysed here),

these aspects (all the examples and the terminology used here are originally in Japanese, the translation is mine and not literal).

9 Levinson's remark that "even sentences in explicit performative form can be used with different illocutionary forces from those named in the performative verb" (1983:274) exemplifies the case discussed here in 2.2; see also Leech (1983:114); Lakoff (1973:295), and Meier (1995). 
shows a systematic pragmatic manipulation with a variety of often widely diverse contextual effects, in which 'negative' strategies can bear 'positive' implications as well, a mechanism also pointed out by Meier (1995:384).

One further point that needs to be reconsidered is Ide's observation that the description of conventionalised, situation-bound honorifics has been penalised by B\&L's insistence on the speaker's intention and the 'rational', 'calculable' aspect of linguistic politeness (Ide 1989:243). This is a very legitimate observation (acknowledged in fact by B\&L themselves) but her own identification of linguistic devices and (this time different) underlying principles seems only to perpetuate B\&L's shortcomings (see again Meier 1995 for a discussion of the latter, and also Okamoto 1997).

Ide and Matsumoto emphasize the importance of social norms over individually motivated stances of the speaker and presuppose a rather clear-cut separation between the two poles. Whilst it is easy to agree that the distinction is a useful heuristic tool, one wonders if -under performance- it is always unequivocal. The borderline between behaviour that simply abides to norms, and behaviour that originates in an individual's expressive intention can be extremely difficult to pinpoint. From a cognitive viewpoint, external (social) and internal (psychological) motives can be difficult to discriminate, and awareness of one's acts of volition can be commonly conceived in terms of commitment to an idealised norm of appropriate behaviour ${ }^{10}$. From the viewpoint of verbal behaviour, the two factors are likely to interact dynamically with the specific contextual features of

10 Epitomic cases are forms conventionally referred to as Bikago (or Beautification forms). A typical example is the use of the honorific suffix $o / g o$ to refer to the speaker's belongings or actions, like in $O$-heya ('room') for the speaker's own room. Ide (1982:378) considers these a phenomenon of 'hypercorrection', whereby a speaker attempts to demonstrate his command of a 'polished' register by means of refining his own speech. Ide claims that this can be viewed as an attempt to "impress others", rather than to follow the "social rules of politeness" (1982:380). Even so, in order for an option such as this to be elected at all, it must represent (or be perceived as representing) some form of prescribed, appropriate parameter in the construction of a specific 'image'. 
the encounter, and are likely to be present synchronically in discourse, though differentially relevant.

In sum, what is highlighted in the Japanese scholars' work is the pressure of language on speakers, and of social settings on language. The choices a Japanese speaker is forced into, both grammatically and socio-pragmatically, are profuse and all-encompassing, and according to Ide and Matsumoto, so strongly constrained by social conventions, themselves dictated by members in powerful social positions (Watts et al., 1992:5), that Japanese speakers seem to have little expressive leeway, at least on the level of interactional management.

Finally, it could be noted that their total rejection of B\&L's notions of face, whilst on one hand allowing the development of a notion of appropriateness, has prevented them to paying attention to the role of positive strategies in the construction of such appropriateness.

The following paragraphs concern themselves with a re-examination of these issues: the applicability of B\&L's notion of 'face' to Japanese, the role of honorific devices and verbal strategies in the negotiation of it, and the underlying criteria that allegedly regulate Japanese in a manner qualitatively and quantitatively different from English and other languages. In order to do this, in 2.1. I will re-examine the routine formula discussed by Matsumoto and sketch out first observations; these will be illustrated further in 3 ., an analysis of some Japanese honorific devices.

\section{An alternative analysis of a controversial Japanese routine formula}

The formula doozo yoroshiku onegai shimasu constitutes one of Matsumoto's arguments for rejecting B\&L's hypotheses and confute their claims of universality for the notions of 'face' and 'deference'. Her argument proceeds more or less like this: deference does not necessarily entail recognition of the right to immunity, if there are Japanese conventional 
expressions such as this, that convey deference but take the shape of an imposition. This formula is typical of deferent behaviour because the speaker humbles himself, yet he does so through an imposition. Moreover, the speaker is not expressing positive politeness because for B\&L that is typical of intimate behaviour, whereas this utterance hinges on the notion of rank difference (Matsumoto, 1988: 409-10). The natural corollary is that the constituents of 'face' must be different in English and Japanese. While referring to her observations on this formulaic expression, I will highlight some aspects of her linguistic analysis that exemplify problematic methodological issues, and propose an alternative reading.

\subsection{Doozo yoroshiku onegai shimasu: lexical, morpho-syntactic and discoursal} features

Doozo yoroshiku onegai (ita)shimasu is utilised principally when someone is introduced, or introduces himself to someone else. The conventional gloss in the latter context is "Pleased to meet you", whereas its literal meaning would be something along the lines of $<$ Please treat me favourably/ take care of me>; it can also be used 'on behalf' of third parties (generally a member of the speaker's family/group/circle, or the speaker's miuchi) as in: musume o doozo yoroshiku onegai shimasu, "Please treat my daughter favourably"; it can be used towards a single or multiple hearers (as it often happens in jiko shookai, self introduction/presentation in social encounters like gatherings, meetings, etc. ${ }^{11}$.

\footnotetext{
${ }^{11}$ Additionally, it is used as a conventional formula in New Year's greetings, both in oral and written form, as a ritualised request for future patronage, often accompanied by a preamble with thanks for the favors (real and metaphoric) received in the past year: Sakunen wa taihen osewa ni nari arigatoo gozaimashita. Honnen mo doozo yoroshiku onegai itashimasu, "Thank you very much for all your kind help during the past year. I hope I can continue to count on your guidance this year."
} 
Whether the 'request of favour/patronage' is interpreted as a literal or a metaphorical request depends largely on contextual conditions, such as the existence of a (previous) request in the background, the actual or assumed capacity and/or obligation of the hearer to comply with it, etc. In an introduction to my future boss, it is very likely that my uttering "please give me guidance" will be felt by my interlocutor(s) as rather salient and therefore sincere. In contrast, in a context in which the nature of the speaker and the hearer's future relationship is still indefinite, a rather generalized, metaphorical, and therefore ritual reading is likely to be preferred.

Despite briefly making allowance for other possible interpretations (1988:410), Matsumoto maintains that: "The speech act in question is a direct request; thus, an imposition" (1988:410, and similarly in 1993:63). As she does not discuss her statement in more detail, we must assume that her judgement is based on the presence of the explicit performative negau (to ask, to request), in a declarative form. Aside from the problematic issue of assigning an unequivocal illocutionary force to a declarative utterance (or, for that matter, to many other types of utterances) the presence of a performative notwithstanding, other elements of the utterance seem to point in different directions.

Firstly, the specific 'humble' structure of o/go-V-suru/itasu (see Ohso, 1987; Kikuchi 1996:60, Martin 1975:344) not only denotes status differential, but is also strongly constrained by the nature of the predicated action, that must be relevant to, or result in a positive effect on the hearer (or a referent), as in 2 or 3:

2 go-chuumon no shinamono o o-mochi shimashita HON order goods ACC bring [HUMBLE, FORMAL] PAST

I have brought (you) the goods you ordered.

3 go-shookai shimasu

introduce [HUMBLE, FORMAL] non-PAST

Let me introduce you

The restriction that there cannot be adversative effects on addressees or referents to whom the utterance is oriented is a crucial feature of this construction (Martin, 
1975:344), which a later paper of Matsumoto (1997) quite significantly labels 'benefit transfer condition'. Hamano (1993:86) stated this condition in a symmetrical way, by indicating, as a necessary pragmatic condition of use, the "non threatening nature of the action to the exalted party". In order to explain why verbs such as manabu 'to learn' or narau 'to learn' cannot appear in this form, she further adds: "The action must not be self-centred" (1993:94).

To be sure, selection of this form has a lot to do with rank-related considerations. Strictly speaking, however, this is not because the humble form indexes social status 'directly', but rather because of the restrictions that such status entails on its use, as constraints on the range of acts that are permitted at all of a speaker in that particular role and with that particular status. This causes a more complex interpretation of its value, as will be shown in a moment. Lacking the condition of non-adversative effect, the use of the humble $o / g o-V$-suru/itasu is inappropriate even if it correctly indexes the hearer as a higher. This is demonstrated by the following utterances with the same predicate: whereas it is easy to imagine the situation in 4 , it is not so for 5 , due to the conflictual meanings conveyed by the semantics of the utterance on one hand, and the morphosyntactic connotations of the predicate on the other (which index a superior hearer and imply a number of associated rights).

[student to teacher]

4 kurasuno minna no iimeeru adoresu o o-kaki shimashooka. class GEN e-mail address ACC write [HUMBLE, FORMAL] HOR INT Shall I write down the e-mail address of everyone in the class for you?

5 ?sakubun o o-kaki shimashooka. essay ACC write [HUMBLE, FORMAL] HOR INT Shall I write an essay for you?

A crucial remark in Hamano's paper is the one that explains apparent exceptions to the pragmatic norm that licenses this humble form, such as:

6 Kodomo ga senseei ni gomendoo o o-kake shita child SBJ teacher GOAL caused inconvenience

My child made the professor go through the trouble (I appreciate it).

7 Omatase shimashita 
kept one waiting

(Sorry) I have kept you waiting.

(1993: 98). Hamano's view is that “verbs denoting actions causing nuisance or special trouble on the part of the exalted party can be used in nonsubject honorification, provided that they are used to express the speaker's gratitude for the exalted party's understanding" (1993:97, my emphasis). Matsumoto's interpretation of these cases is that "the target of honorification is presented (by the speaker) as bestowing a benefit rather than receiving a detriment" (1997:733). Whatever the version, it is clear that actions predicated in this syntactic form cannot be impositions on the hearer or any referents, a conclusion that conflicts with Matsumoto's original attribution of the utterance force and of the role of impositions as vehicles for deference.

The second element at odds with the presumption of an imposition is the modal adverb doozo. Doozo (roughly 'do go ahead') presents a complementary distribution with sumimasen ("pardon me", "excuse me"), and its use can transform a request (benefit to S) into an invitation or an offer (benefit to H), as shown by Himeno (1991:70-71, citing Koizumi, 1990:262):

8 sumimasen ga, mado o akete kudasai. window ACC open AUX-IMP

Excuse me, would you open the window (for me) please? [request]

9 doozo, mado o akete kudasai window ACC open AUX-IMP

(Feel free to) open the window (if you wish). [invitation, permission] $]^{12}$

12 That doozo is constrained by the existence of a benefit to the hearer can be tested further in the following example, in which its cooccurrence with a predicate that connotes a benefit to the speaker and not the hearer (a honorific auxiliary in the negative interrogative form makes 1 unacceptable; an additional test is provided by its incompatibility with simple imperative forms (forms not accompanied by auxiliaries, that we would expect to be the canonical type of imposition), as in 2 (Himeno 1991:70).

$1 *$ doozo, mado o akete kudasaimasen ka window ACC open AUX-NEG-INT

$*<$ go ahead and $>$ won't you open the window for me?

$2 *$ doozo, mado o akenasai 
(my translation and glosses on all these and the following examples).

Since Himeno, followed by Matsumoto, maintains that the fundamental usage of this adverb appears in invitations, she cannot but conclude that its utilization in the formula doozo yoroshiku onegai shimasu is to be considered an exception (1991:72, n. 2); interestingly though, Ohso had already noted the idiosyncrasy of this adverb, which can occur in begging, but not in orders and requests:

10 onegai desu kara, doozo, inochi dake wa o-tasuke kudasai beg COPULA life TOPIC help [HUMBLE] AUX- IMP I beg you please, spare my life.

But she concludes more consistently that: "Doozo yoroshiku onegaishimasu (which is untranslatable into English) is a stylized form of a case of begging." (Ohso 1983:148) ${ }^{13}$.

On these grounds, and in absence of any compelling evidence that the formula in question is a straightforward request, one can only conclude that there is nothing exceptional in the use of this adverb, and that the general sense of the utterance goes beyond that of an imposition. In Leech's words $(1983: 94,104)$, there is no conflict between the social goal (of maintaining the Politeness Principle) and the illocutionary goal (of greeting). If the distributional characteristics of doozo indicate a case of begging (if not an invitation), the humble form $o / g o-\mathrm{V}$-suru indexes status differential but most of all denotes an act done for the hearer: if anything, both facts provide support to the view that the main function of the formula is a prevalently 'positive', face-giving one. Since the hearer is the recipient of 'deferential' begging (as he is the recipient of 'deferential' delivering in example 2, and 'deferential' introducing in 3), he is regarded as a person of prestige and authority that has the power to bestow favours.

The reciprocating reply, also discussed by Matsumoto (1988:411):

11 Iie, iie, tondemo gozaimasen. Watakusi no hoo koso yorosiku onegai itasimasu.

window ACC open IMP

$*<$ go ahead $>$, open the window for me.

13 It might be worthwhile to remember here B\&L's note that "orders and entreaties (begging) [...] have inverted assumptions about the relative status of the speaker and the hearer" (1987:96). 
"No, no, not in the least. I am the one who asks you to treat me well." is no reply to a request but, quite appropriately, a response to the implication of the utterance (in Japanese not so much implicated but overtly marked), i.e. a highly conventionalised $^{14}$ and ritualistic negotiation of the role of benefactor/patron/superior etc. in a given situation.

\subsection{Preliminary conclusions and further hypotheses: positive politeness reconsidered}

The features of this greeting formula that I have discussed above do not support Matsumoto's interpretation of the formula as a straightforward imposition, and this at least weakens, if it does not invalidate, the hypothesis that in Japanese even imposing on the hearer can convey politeness. Rather than constituting evidence of the inapplicability of B\&L's notion of deference to the Japanese language, this discussion highlights some facts about the workings and the role of greeting formulas that indeed are better accounted for as instances of positive politeness.

One can look at the honorific devices in this formula (negau is a humble verb, o/goV-suru is a humble syntactic structure) as redressive strategies for the FTA of 'requesting' (or the potentially FTA act of greeting?); yet the discourse function of this utterance as the opening of an encounter, can more intuitively be interpreted as an implicit -yet transparent- message of the speaker's appreciation of the hearer's social persona, a very clear instance of positive politeness. Like many other routines and the 'small talk' in the opening phases of the interaction, also the mutual ritual recognition of ranks, skills, expertise, or authority represented by routines like the above helps

\footnotetext{
${ }^{14}$ See Levinson 1983:129 for honorifics as conventional implicatures.
} 
participants to establish an atmosphere of co-operation, comity, harmony, solidarity, that eases the relation 'on track' from the outset (Laver 1984:218) ${ }^{15}$.

As for the expressive effect of the humble forms, which certainly can function as social indices, their pragmatic multivalence is a well known mechanism: the saying jibun o herikudaru koto ni yotte aite o tateru ("by humbling oneself, one elevates the hearer") appears frequently in Keigo (Linguistic Politeness) manuals (Ooishi, 1986:99). The semantics of the specific humble structure selected (pointing to the relevance for, and the potential benefit to the hearer of a proposition $p$ ) testify to the generally positive function of this expression. The use of indexing devices (the humble forms), plus the modal adverb that accompanies offers/invitations, are displays of the speaker's willingness to pay respect to the hearer's face, not to impose on him.

The speaker's degree of 'commitment' to the meaning conveyed by the formula may, as pointed out earlier, be contextually variable: a higher-ranking person may utter it metaphorically, a subordinate more literally. Its reading depends to a large extent on the mutually perceived status and role, and its selection is motivated by the kind of image the participants wish to project of themselves: the higher-ranking person appealing to notions of chivalry or magnanimity (see also Hymes 1986:82), the lower-ranking to one of reliance. With small differential values of $\mathrm{P}$ the interlocutors do so simply to pay respect to each other by means of the virtual attribution to the addressee of the leader's role ${ }^{16}$.

15 Laver sees phatic communion in conversational openings as interactional work aimed at reducing uncertainty and generating solidarity, and as a set of strategies with 'propitiatory', 'exploratory' and 'initiatory' functions. When mutual status assumptions are not clear to the interlocutors "the process of phatic communion allows them the opportunity to explore, in a tentative way, the social identity and momentary state of mind of the other participant, in order to be able to define and construct an appropriate role for themselves in the rest of the interaction" (1984:218).

16 Whereas this is to a greater extent the concern of the lower-ranked person in unequal (non-intimate, asymmetrical) encounters (which may indicate a somewhat opportunistic nature of this behaviour) a higher- 
Small values of perceived D may not trigger this ritualistic foreplay altogether, as negotiation of roles, and of one's image in the other's eyes, may not be an issue at all.

Matsumoto is right in stressing the need of both participants to conform to the expected social role. But since she postulates the existence of a threat to the hearer's negative face (an imposition) and must therefore resolve the contradiction with the conveying of a deferential attitude, she proposes to "abandon the universality of negative face" (1988: 410).

According to the alternative analysis proposed here, all devices in this particular expression -modal adverb, humble forms, the begging- converge to construe what Geis (1995:102) would call a face respecting act (FRA), and Kerbrat-Orecchioni (1997:14) a face enhancing act (FEA). Geis argues that there are no reasons to think that displays of positive politeness need to be construed as a redress for threats. We need not be constrained to view politeness within a theory of speech acts, but the important point is that to envisage positive politeness as redressive action (albeit "less redressive", B\&L, 1987:17 and ff.) that is typical of intimate behaviour, is an extremely reductive position, with two major consequences. The first is a counterintuitive - if not counterfactual implication that behaviour in non-intimate encounters can do without positive politeness, and the second is the onus of explaining any non-intimate behaviour marked by politeness-related devices as instances of redressed FTAs, hence a proliferation of FTAs the problem exemplified by, but not limited to, Japanese, and a rather misanthropic view of human interaction (or at least 'overly pessimistic', as in Schmidt 1980:104).

Certainly many non-intimate symmetric relationships require a big deal of ritual mutual reassurance about one's intentions (and therefore redress of an assumed potential threat), but they also and most of all require the setting and maintenance of mutual assumptions of appreciation (a supportive function, Held 1989:201). This need is by no

ranked individual's use of positive politeness strategies may be motivated by what today we would call 'political correctness', again not entirely free from an egocentric finality. 
means exclusive to intimate relationships. Especially in non-intimate encounters, one would consider display of 'polite' behaviour (here rather in the sense of positive behaviour) to be informed by the need of projecting a desirable, likable, appreciable image of oneself, if social acceptance and recognition are less 'obvious' than in intimate encounters, and require negotiation.

This characterization of positive image is consistent with Goffman's (1972:5 ff. $)^{17}$. For him, 'face' is first and foremost a "positive social value a person effectively claims for himself [...], an image of self delineated in terms of approved social attributes" (p. 5) the achievement and maintenance of which are a fundamental social constraint. When claiming face, we claim most of all a positive face. Since "One's own face and the face of others are constructs of the same order" (p. 6) then rules of self-respect and of considerateness lead a person to strive to maintain both his own and others' face (p. 11). In other words, these are two aspects of the same coin, but insofar as a person's social existence is subordinated to recognition by others, his uttermost concern is to create and maintain a positive image of himself ${ }^{18}$.

The setting and maintenance of mutual assumptions of appreciation is clearly a 'global' need better accounted for with the notion that Watts denominates 'politic behaviour'. For Watts (1989:135) the "socio-culturally determined behaviour towards the

${ }^{17}$ See also Bargiela's (in press) illuminating article on the necessity to return to Goffmann's original notion of 'face' (unduly dichotomised and biased toward 'negative' needs in B\&L) in order to re-conceptualise politeness correctly.

18 Castelfranchi $(1988: 14,17)$ also defines (the gaining of generally positive) face as an individual's (super)goal, whose function is to obtain adoption of one's goals by others, and therefore power. An individual can try to achieve his goals on his own, but to have others adopt his goals increases his chances of success. To the extent that face maintenance is instrumental to increasing chances of success of achieving one's goals, or of achieving power, this implicates interdependence. Seen in this light, negative strategies can be subsumed under a general effort to gain positive face (see the final section for a discussion of this point). 
goal of establishing and/or maintaining in a state of equilibrium the personal relationship between the individuals of a social group [...] during the ongoing process of interaction" constitutes 'politic behaviour'. This is crucially irrespective of the type of linguistic devices utilized to this purpose (Watts, 1989:136, 1992:57), and I should like to add, of the 'orientation' (positive or negative) of the linguistic strategy employed. Breaking this equilibrium by defect leads to 'non-politic' or even impolite behaviour, whereas breaking it in excess (i.e. ego's attempts "to enhance her/his social standing with respects to alter", Watts, 1992:57) generates instances of 'polite' behaviour, whose nature is thus postulated as fundamentally egocentric. (This paper generally subscribes to this characterization of politic behaviour as the unmarked 'stabilizing' behaviour. Hereafter explicit distinctions will be drawn whenever it will be necessary to appeal to the notion of 'politic' in contrast to 'polite' behaviour as from this framework). From this perspective, routine formulas like the one above simply contribute to appropriate behaviour (as long as their use is unmarked) regardless of the specific strategy (negative or positive) they hinge on. Verbal strategies (deferential begging) and formal forms (the various sociolinguistic markers) converge dynamically - via non-propositional indexing and/or inferable implications towards appropriateness. They do so by designing a complex chart of negative and positive tactics ('overtly mark subordinate status and social distance', 'show reliance', 'appeal to authority', etc.). Attending to both face needs is mandatory to the extent that we need to be appropriate.

More evidence of the strategic use of formal forms will be discussed in the next two sections, respectively on 'Addressee' and 'Referent honorifics'.

\section{Addressee and Referent honorifics}

A remarkable amount of modal information in a Japanese utterance is conveyed by suffixes clustered on the (sentence final) predicates; among these, 'style markers' are 
responsible for the indexing of speech levels; these are therefore labelled 'honorifics of the addressee' and their use is constrained by the power- and distance-relationship between the speaker and the hearer, or their vertical and horizontal distance ${ }^{19}$ :

12 kyoo wa doyoobi da/desu/degozaimasu today is saturday

Today top saturday copula [plain/polite/superpolite]

13 uchi ni kaer-u Ø/ kaer-i-masu I'm going home

home return-non past [plain-polite]

On the grounds that these forms constitute a grammatically and socio-pragmatically obligatory choice and that they are limited in number (Ide 1989:227), Ide's paradigm assigned these forms to a different category to that of verbal strategies (recall the scheme at p. 6). However, a look at the mechanism by which either 'formal forms' or 'verbal strategies' 'mean' politeness, reveals that they remarkably similar in nature. Generally speaking, style markers or honorifics are not much more predictable than polite verbal strategies. It is true that the 3 different possible markers -da/-desu/-degozaimasu in the Japanese variants of 'today is saturday' force the speaker to a grammatically and pragmatically obligatory choice in order for him to sound appropriate, but so do different illocutionary formats -different 'strategies' or realizations- of the same propositional content (as well as the type of possible propositional contents themselves). For instance, whether I craft a request in the shape of an order, a negative question or a hint, equally depends on sets of constraints of pragmatic and linguistic nature, be that felicity

\footnotetext{
19 I consider honorifics to be constrained by the hearer's and speaker's mutual attributes in the sense that the relevant attributes at a certain time determine the stance of the interlocutors towards each other, and this positively contributes to 'determine' the setting. A setting can thus be subsumed under the particular type of relationship in which the speaker and the hearer engage at any one time. When two interlocutors switch from formal markers in an institutional setting to informal markers in more private circumstances, we can describe this from the viewpoint of the setting -that hence constrains participants- or from the viewpoint of the speaker -that hence assumes a stance that allows him to constitute that setting (see Ochs, 1996:414). Clearly this is a point of contention with Ide (1982)'s view, that sees the setting as an affecting factor external to the participants themselves and hence posits settings as 'overriding rules'.
} 
conditions, sociolinguistic notions, or the semantics of the language ${ }^{20}$. Issues of relevance, as argued by Jary (1998) on politeness, govern the selection of the appropriate speech act. In relevance theory terms, different verbal strategies force the speaker to grammatically and socio-pragmatically obligatory choices necessary in order to select the 'optimally relevant' stimulus (to achieve 'politic behaviour').

Just as honorifics are regulated by the social relationship between speakers and addressees, verbal strategies are also constrained by 'global' notions of rights and obligations of members of society with different attributes (different 'ranks' or different degrees of intimacy -notions subsumed by definitions of $\mathrm{P}$ and D). How honorifics can be strategically played upon to produce interactional effects will be discussed in more details below. Here I will conclude by emphasising the point (also discussed in Jary, 1998:12) that 'up-grading' a verbal strategy - e.g. asking when one could order - may convey the speaker's concern for (redressive) face-work and be an act of 'volition', but cannot be exploited ad libitum without a risk of triggering detrimental implications (very much like with honorific markers - e.g. displaying deferential distance when one could be more casual). Thus, the real import of a verbal strategy must nonetheless be anchored to rankor role-related general norms and expectations (recall that this has been discussed in 2.1

\footnotetext{
${ }^{20}$ The 20 different Japanese variants of the utterance "can I borrow a pen" described by Hill at al. (1986), which are all istances of "verbal strategies', do not just vary in relation to social indexing but also in relation to contextual applicability. Within the 'informal' sub-group itself, diverse utterances would be included such as statements: kariru yo. ('I'll borrow that') or kashite hoshii n da kedo. ('I'd like you to lend me...'); an imperative kashite(yo). ('Lend me...'); a question: aru? ('Do you have...?'); a S-centred request: karite ii ('Can I borrow...?'), and a H-centred request kashite kureru ('Will you lend me...?'), etc. The choice among these surely depends on factors included in the computation of $\mathrm{W}$ (such as degree of intimacy, rights of the speaker to request, and a notion of cost of the action), but also on felicity conditions that would make an imperative less appropriate than a question when the speaker is not sure if the hearer has a pen at all; a statement less appropriate than a request if the speaker is unsure that the hearer is willing/able to lend it, etc.
} 
on the constrains that regulate o/go-V-suru/itasu). This makes verbal strategies technically akin to the 'formal forms'.

In sum, criteria of social and situational appropriateness apply equally to any device, but since 'formal forms' are conspicuous, non-propositional and more conventionally bound to 'global' elements (social traits of participants) they tend to be perceived as relatively more stable than norms that regulate the choice of an appropriate verbal strategy -a choice from a range of paradigmatically related, contrasting illocutionary forces. In fact, the degree of stability of 'formal forms' is directly proportional to the magnitude of $\mathrm{P}$ and $\mathrm{D}$ : intermediate/middle/central values of these factors are likely to generate higher intracultural and interactional variability ${ }^{21}$.

\subsection{Addressee Honorifics}

Before briefly reviewing studies on the strategic use of style markers, let us recall B\&L's classification of honorifics: these are devices that express the speaker's deference toward the hearer by exploiting the sense of 'P differential', and so indicating that the speaker recognises and is not willing to trespass the hearer's territory; a negative strategy, naturally redressive of an FTA $^{22}$. However, two points of their characterization are arguable: first, that what is conveyed by these markers is invariably motivated by FTA redress (the point made by the Japanese scholars), and second, that they carry a constant

${ }^{21}$ Wolfson (1989:129) describes the "bulge" pattern of linguistic behaviour and points out that the degree of "certainty" of the relationship is an important constraint in the use of verbal strategies. Speech acts with a clear social goal such as compliments and responses, invitations etc. display similar patterns between intimates, status unequals and strangers, distinctly different from those between non-intimates, status-equal friends, co-workers and acquaintances.

${ }^{22}$ B\&L admit, in their reassessment of 1987, that honorifics and address forms "may occur with an FTA of any value and thus equally with markers of positive and negative politeness" (p.18). What I object to here, is their insistence on tying honorific occurrences with FTAs. 
meaning of 'deference' (a point on which both B\&L and the Japanese scholars are not very clear).

I submit that the 'polite' honorifics of the addressee -desu/-masu can be seen as devices that carry a prototypical 'meaning' of [+distancing], but a meaning that is actualized differently in different contexts, or that realizes rather different speaker's stances. I will illustrate this after a review of some previous studies on this subject.

Examining the mechanisms involved in the mixing of styles in discourse, Ikuta (1983) identifies 'empathy' and 'discourse cohesion' as two main motivating factors. Commenting an example where a shift towards [-distant] occurs in an otherwise [+distant] environment, she claims that [-distant] marks an empathetic utterance that "supports more strongly the person receiving the positive evaluation" than a [+distant] utterance would do (p. 43); and (in the corresponding note) that [-distant] can thus "work as an expression of "positive politeness"". She remarks elsewhere that "social restrictions [...] are, of course, the main determinants of what appropriate level to choose in a particular social situation. But there is a difference between such factors and the empathy factor; that is, the former serve as 'constraints' whereas the latter is a 'strategy"'. She concludes that: "Social factors are, therefore, obligatory, while the empathy factor is optional" (p. 42). This would support Ide's argument, had she not linked obligatority and optionality to different linguistic features (respectively 'formal forms' -honorifics- and 'verbal strategies'). Ikuta's argument on the effects of shifting down does not indicate that face-work can be or is 'abandoned' momentarily for whatever discoursal reasons. It indicates that style shifting is one of the very functions of face-work.

Usami (1995:33) observes that 'shifting-down' from use to non-use of polite forms within an exchange marks an act of joking (and concurrently a move towards psychological 'closeness'), and that stylistic 'accommodation' to a previous downshifting by the hearer represents an instance of psychological alignment. Similarly, the same downward switch can index the shift to a discourse type in which the transactional aims 
(or clarity of the exchange) override the interactional ones, as in requests for clarification. Conversely, 'shifting-up' from non-use to use of polite forms can be used to mark the introduction of a new topic, or again accommodation to the interlocutor's 'upgrading' of the general tone, etc. Noda (1998:96) additionally notes that utterances that appeal to the hearer directly, such as questions or suggestions, are also marked 'politely' even in otherwise consistently plain contexts.

A particularly interesting case is that reported by Mimaki (1997:66) where during an exchange between two long acquaintances in the 'public' frame of an interview setting, accordingly marked with relatively high degree of formality by the female speaker she suddenly downgrades the speech level when she addresses the hearer with a criticising remark (a definite FTA), and by doing so evokes a more intimate, personal dimension. Since the relationship between the speaker and the hearer is a long-standing one, the (macro-)social goal of maintaining an intimate relationship is not threatened by what, at the illocutionary level, seems to constitute a competing effect, but, if anything, underlines it.

Finally, Maynard (1992) argues that 'stylistic' motivation alone cannot account for style variation in Japanese and explores alternative cognitive and social sources. She provides extensive samples of texts where the two different speech levels are systematically manipulated to indicate variation between the two poles of what she defines: situations of 'low' and 'high' awareness of the other. Whereas sudden recalls, exclamations, vivid narrations, self-reflecting thoughts, joint utterance construction, backgrounded (i.e. semantically subordinated) information and deliberate expression of closeness represent "low awareness situations', information or thoughts directly involving the addressee, or deliberate expression of formality represent 'high awareness situations'. She concludes: “The mixed style reflects the speaking self's choice as to how the utterance is located in the low and high points within the scale mentioned above" (p. 179). 
Surely not all the uses described above are motivated by a speaker's concern for facework (for instance considerations of 'discourse cohesion'), but at least some of these occurrences certainly are. In the following setting (two police officers observing a girl in a bar) the same speaker utters 11 and 12 sequentially. Whereas the first is a sudden and spontaneous description of incident, the shift to the formal utterance is motivated by the need to "design an utterance appropriate to and appealing to the hearer in that context" (Maynard 1992:159):

\section{Hitori dete kita. (abrupt)}

one person appeared

'A person is coming out'

15 Ano ko desu yo. (formal)

that child be ip

This is the very girl.

However, that face-work motivates manipulation of honorific markers is not tantamount to saying that what is communicated is consistently or unequivocally 'politeness'. In the same way that many English verbal strategies have a wide range of potential meanings, occasionally coinciding with polite meanings -e.g. 'if' clauses (B\&L 1987:162), metaphors (B\&L 1987:222), etc.- Japanese honorifics also exhibit the same multivalence ${ }^{23}$. They can convey politeness contextually, and they do so by means of reference to a range of other stances ${ }^{24}$.

23 Minami Fujio's (1987) taxonomy of the 'features of treatment' of an addressee provides a potential inventory of what $\mathrm{I}$ have referred to in this paper as speaker stances. He describes Japanese honorifics as devices that can have a bearing on any of the following expressive features (translation based on Minami's 1974 own English summary): High (age) vs. Low (sage); Distant (hanare) vs. Close (chikazuki); Formality (aratamari) vs. Informal (kudake); Trouble (owase) vs. Oblige (oi); Weak (Jaku)vs. Strong (kyou); Elegant (Bi) vs. Vulgar (Shuu); Indirect (Kansetsu) vs. Direct (chokusetu).

Seen in this light, and side to side with considerations on politeness from a Relevance Theoretical perspective, even relatively 'dedicated' devices such as honorifics seem to convey something different from politeness in a narrow sense. For a review and a discussion of the diverse functions of Keigo, see for instance Kokuritsu Kokugo Kenkyuujo 1990, vol I:91, 95. Tsujimura (1992:191) discusses self-oriented 
Here I should like to refer to the notion of 'index' discussed by E. Ochs (1996). She characterizes language as a system of indices, which can point, simultaneously, to disparate dimensions such as social identity, type of act performed, affective and epistemic stances of the speaker etc. However, she points out that "it is important to distinguish the range of situational dimensions that a form (set of forms) potentially indexes from the range of situational dimensions that a form (set of forms) actually indexes in a particular instance of use". The former "derives from a history of usage and cultural expectations surrounding that form" and the latter is differently construed by the speaker the hearer and other participants (1996:418), supposedly on the basis of contextual interpretation as well as their linguistic and socio-cultural competence.

If we look at honorifics from the viewpoint of the stances they index, then, for instance, -desu/-masu [+distancing] can be associated, among other things, with deferential or self-protective behaviour between interlocutors of different status as well as simply 'prudent' behaviour between non-intimates; it can be employed in formal settings to connote a 'public' tone, or it can underscore emotionally charged stances (as for instance, when the speaker deliberately adopts a 'cold', distant, tone); not surprisingly, it can be associated also with behaviour between intimates in an ironical, joking 'key'.

Conversely, [-distancing], or 'closing in', using the plain forms $-d a /-\varnothing$, may index the speaker's acknowledgement of closeness in an interaction between intimate friends, but an aggressive attitude in an interaction with a superior (via a breach of the hearer's territory), and so on (see also Okamoto 1999).

politeness (jiko shikoo no keigo) and claims that it is nonetheless 'genuine' politeness as its effects invariably extend to others. Even cases of Bikago, by definition a mere device of refinement of one's own language, are never entirely independent from a concern for others. For Tsujimura both aspects are actively involved on the whole of Keigo.

24 See Ochs (1993:152) on what she terms the "non-exclusive" property of the relation between language and social identities. See also Agha (1994:279) for a review of research on the fuzzy relation between terms of address and social dimensions. 
In this sense then, one can see that even relatively dedicated markers of social indexing can be and are exploited strategically ${ }^{25}$. (Conformist or deviant) use of these markers simply helps connotating (expected or novel) stances of the speaker towards the hearer with regards to their social roles, such as intimate vs. stranger, lower- vs. higher-ranking, elder vs. younger, as well as more specific situational attitudes, such as 'public', 'emotional', 'unfriendly', 'politically correct', etc. Thus, broad social dimensions such as status, age or gender, contribute to 'framing' the interaction, and against such frames 'deviant', 'unexpected' uses convey other dimensions of psychological nature ${ }^{26}$, which

${ }^{25}$ See Okamoto 1997 for a discussion of the same point with regards to Japanese interactional particles. I am reluctant to define these markers as direct indices of social identities following Ochs' argument that social meanings are derived pragmatically not from the linguistic evidence, but rather from the assessment of the particular stances which that evidence defines. I will come back to this argument in my conclusive remarks.

With regards to the strategic use of honorifics, this can be observed also at the diachronical level. B\&L maintain that many conventional routines are crystallized forms of inferential strategies. Surely there is little 'rational' or strategic in the interpretation of the verbal suffix -masu (an addressee honorific) today, but its etymology reveals a rational exploitation of its semantic implication. Kubota (1993:152), like B\&L, claims that the origin of the use of -masu is in the referent honorific with humble value mairasu ('to give': Toyama 1977). The stabilization of that meaning becomes the condition for extending the use of the form to new contexts, which generates a functional shift that is never totally arbitrary (B\&L, 1987:277, and Held, 1989). This is consistent with Matsumoto's (1993:64) assertion that -masu uses originate in 'rankordering', but the etymology underscores the strategic exploitation of an indexing device.

26 Leech (1983:12) discusses "standing features such as the social distance between participants" and "dynamic features such as the illocutionary demands the speaker is making on the hearer"; Usami (1995:40) talks of "global elements" such as age, gender and social status, and "local elements" such as linguistic context and psychological posture"; Jary (1998:11) discusses communicators' "long-" and "shortterm" aims; see Watts (1992) and Jary (1998) for an interpretation of 'deviations' in terms of relevance theory.

In Watts (1992), departure from expected behaviour in the use of terms of address conveys polite rather than just politic behaviour when deviating 'upward', and non-politic behaviour when deviating 
may still serve face-work related purposes. 'Discrepancy' not only generates sociopragmatic pas faux (Ide 1989:227) or undesired 'interactional implicatures' (Matsumoto, 1988:415) but also allows systematic and deliberate expressive uses, which can be indeed FTA-sensitive (as also pointed out by B\&L, 1987:181) ${ }^{27}$.

Neither the presence of honorifics in Japanese nor the mechanics of their strategic usage demonstrate that Japanese places a "higher value" on recognition of social ranks than on redressing impositions (Matsumoto, 1988: 421). This could only be demonstrated by evidence that impositions can systematically be condoned provided rank is attended to, but Matsumoto fails to provide any such evidence (and none has emerged to my knowledge otherwise). At best, one can conclude that the indexing of social ranks serves as the anchoring background against which specific illocutionary acts are assessed differentially.

B\&L's categorizations of polite strategies as redressive work oriented to negative or positive aspects of the speaker's or the hearer's faces, has been shown to be inadequate by Matsumoto and Ide's emphasis on the significance of face-work even and especially in absence of threats to face. But especially if one is, like Matsumoto, concerned with deemphasizing the need of 'freedom from imposition' (and hence notions of redress)

\footnotetext{
'downward'. The research reviewed in this section provides evidence of the rich range of expressive meanings generated by 'shifts' in Japanese honorifics. Although the Japanese cases discussed here can be subsumed under his categories of 'non-politic' and 'polite behaviour', they do not seem to be invariably motivated by interactional demands (Usami's overriding transactional needs, Noda's change of topic).

${ }^{27}$ The discussion above may seem to ignore the rather important fact that $\mathrm{S}$ and $\mathrm{H}$ may well hold rather different yiews as to why an honorific should be used (or not used) at all. In other words, I have assumed that the 'meanings' described are communicated and understood homogeneously by the interactants. That this may not be always the case is well illustrated by Okamoto (1999). This fact clearly must be taken fully into account in a theory of honorifics interpretation, but with regards to the current discussion it does not invalidate the argument above that denies that honorifics are interpreted or utilised passively as direct social markers, regardless of the degree of sharedness of an underlying rule.
} 
from the notion of face, and considers all the potential implications of polite devices and strategies, then it is difficult to say unequivocally that manipulation of [ \pm distancing] is only an act of discernment. The functions of distancing devices -e.g. formal forms- show a great deal of overlapping with those of verbal strategies. The picture is much more complex when the immediate communicative goal is assessed against the background of the interactional goal(s).

Whatever the device or strategy, one must assume that appropriate use of honorifics (which includes avoidance as well) invariably produces 'positive' face-work (a somewhat problematic point made by Meier, 1995:385, which I will come back to in the concluding section. See also Held 1989:169). When they are used in compliance with the speaker's and hearer's shared assumptions about each other they 'give' face; both to the hearer, thanks to the speaker's acknowledgement of traits of the hearer's face that deserve recognition in a particular situation, and to the speaker who can claim social membership by means of demonstrating his competence over the relevant social norms. This contributes to what Watts terms 'politic behaviour' ${ }^{28}$, Jary defines as the 'unmarked social indexing view of politeness', Fraser's 'conversational contract view' (1990:232) and it includes use of verbal strategies as well as honorifics ${ }^{29}$.

Ide's clear-cut categorization of devices as either instances of 'Discernment' or 'Volition' suffers from the same flaws as B\&L's criticized attempt to link directly linguistic strategies on one hand to type of face-work on the other. The observations above illustrate that there is a potential overlapping of these two sets of devices if the use of the social markers is also act-sensitive. Volition does not just take place in a vacuum

\footnotetext{
${ }^{28}$ Further research is needed to clarify these definitions since, following my discussion, 'politic behaviour' is also susceptible to be interpreted as self-serving behaviour - any kind of appropriate behaviour pays off in terms of self-image. For Watts an egocentric purpose motivates 'polite' behaviour only, as instances of the speaker's attempt to enhance his own standing with respect to the other (Watts 1992:57).

29 See also Meier 1995:387 on the issue of terminology.
} 
but is constrained by social norms of appropriateness (themselves dictated by culturally determined notions of ranks and roles), and Discernement devices can have a strategic use. Discernment and Volition do not neatly discriminate sets of linguistic devices; they cut across them.

Ide (1989:232) admits, to be precise, that "most utterances are neither purely one nor the other". However, she must do so because utterances can contain a mixture of devices from both of the two principles (as for instance in a politely marked negative question, where formal forms denote Discernment and negation and interrogative markers Volition). I believe it is necessary to conclude so for a different reason: that even strategic devices can represent instances of discernment, and conversely honorifics can vary due to illocutionary demands.

\subsection{Referent Honorifics}

Lastly, I will briefly mention the Japanese honorifics of the referent. These extend to more than one grammatical category, but I will only look at syntactic structures and lexical variants of the predicate. Examples are:

\section{6a. mairu/iku/irassharu}

16b. o-kaki-suru (o/go-V-suru)

16c. o-kaki-ni naru (o/go-V-ni naru) to go [Humble/plain/Honorific]

to write [Humble syntactic structure]

to write [Honorific syntactic structure] ${ }^{30}$

These are potentially required whenever referring to a higher-ranked party; used in 'reporting' actions of a referent, they obviously have little to do with immediate FTA redress, further evidence that carrying out 'appropriate' behaviour is a more allencompassing task than redressing threatening acts. However, also referent honorifics are

$30 \mathrm{O} / \mathrm{go}-\mathrm{V}-$ ni naru (naru= to become) marks actions of a higher-ranked person by means of stressing intransitivity and agent defocusing; o/go-V-suru (suru= to do) marks actions of lower-ranked by exploiting transitivity, or foregrounding agency (Kokuritsu Kokugo Kenkyuujo 1994,vol. II:118). 
not 'fixed' absolute markers of social ranking, but exhibit a very dynamic behaviour, again not necessarily involving redress.

Fukada and Asato (1997:5) observe that utterances that are intrinsically 'impolite' cannot be marked politely without sounding bizarre:

\section{Sensei ga doukyuusei o koroshita}

teacher NOM classmate ACC kill-PAST

My teacher killed my classmate.

18 ?Sensei ga doukyuusei o o-koroshi-ni natta

kill-HON-PAST

My teacher killed my classmate.

The oddness of 18 is caused by conflicting interactional effects. This case shows that, as argued above, global dimensions of status, rank etc. work as 'framing' devices which determine what sort of acts are allowed at all (i.e. a mention of a higher-ranked which is calibrated politely, rules out inherently impolite propositions, and viceversa). If even referent honorifics are sensitive to the type of propositions they predicate, they are not just a static "socio-pragmatic equivalent of grammatical concord", as claimed by Ide (1989:227).

Additionally, studies on the variability in the use of referent honorifics (Kumai, $1988^{31}$, and Japanese work in the early ' 70 s that she quotes) show that a strong pressuring factor is actually the speaker's relation to the addressee - the selection of referent honorifics increasing proportionally to the speaker's assessment of the addressee as

\footnotetext{
31 Kumai's work specifically investigates the humble and honorifics structures listed above as well as auxiliaries of giving and receiving (i.e. metaphorical formulations of actions in terms of virtual benefits to the participants) in a non-FTA, or extremely low FTA act such as a request for information to well acquainted hearers. Whereas B\&L's observations (1987:181) were limited to non-use of honorifics for ingroup referents when addressing out-groups, this study complements those findings by referring to use/nonuse of referent honorifics when addressing in-groups (schoolmates) as well.
} 
higher-ranked ${ }^{32}$. In other words, whether a speaker decides to use a 'polite' verb to connotate actions of a higher-ranking referent, can be primarily determined by whether he ranks the addressee himself as higher than self. The indexing of a polite attitude towards a third party - in absence of specific FTAs to redress - appears to be actually functional to face-work in the here and now of the interaction; indexing of social ranking is not so much a relatively passive (Hill et al. 1986:348) acknowledgment of absolute norms, but yet another strategic device to express individual, personal stances.

Any kind of output can be reduced to being nothing more than the consequence of conformity to mandatory social norms. What needs to be considered here is that while constituting the anchoring reference for pragmatic inferencing, canons of social behaviour are likely to be filtered through a speaker's own parameters (resulting from the speaker's own experience of socialization) and thus are bound to be dynamic, actively constituted or subscribed to by speakers rather than experienced passively. They are likely to be subjectively variable in both relevance (intensity) and scope (Okamoto 1997).

We have observed above that the ultimate interactional effect of appropriate use of referent honorifics can be face-respecting towards the addressee. Similarly however, it can also be functional to self-directed face-work. This has been captured in the Japanese category of Teichoogo, or "courteous/mannerly" usage of honorifics ${ }^{33}$. Some examples in which the referent honorific is syntactically linked to the grammatical subject, but pragmatically exploited towards the listener are provided by Kikuchi (1997:273; I borrow his examples but follow a different line of analysis):

[station announcement]

\section{9 mamonaku densha ga mairimasu}

32 She admits that variable behaviour may be attributable to the speaker's age, these results having obtained from a study of university students. However, similar results for older generations are described in Kikuchi (1996:153).

33 Teichoogo is a term proposed by Miyachi Yutaka, and includes those uses oriented to the addressee by means of a (lexical) Referent Honorific (Tsujimura 1992:125). 
train NOM come - HUMBLE

The train will be arriving shortly.

[in a lecture]

20 puraton ga moushimasu niwa...

Plato NOM say - HUMBLE

As Plato puts it....

Ide would probably explain these occurrences as being motivated by the "needs of the setting". But these settings do not specifically or necessarily require deference (nor these utterances are necessarily interpreted as deferent); they lend themselves, howeyer, to the constitution of a particular social identity: professional, public, or in more general terms, the stance that Maynard denominates 'high awareness situation' (see p.18). In 15 the exploitation of the humble honorific for an inanimate object (by entailing that the object belongs to the speaker's , and not the hearer's territory) evokes the dimension of 'company' (symbolised by the train) vs. customer/(the hearers). In 16 again the association of the referent and the speaker (again entailed by the rules of usage of humble honorifics) is a tool for highlighting the lecture's professional identity (by stressing the affinity of lecturers and content as opposed to the domain of the students) in that particular -and relevant- context.

The constitution of social identities and affective stances can be carried out via a multitude of typically and non-typically 'polite' devices (e.g. other options of register), but also typically 'polite' devices such as honorifics neither uniquely nor directly index politeness. As for the uniqueness issue, we have seen that polite devices can for instance connote public (but not necessarily deferential) stances. As for their being direct, we have observed that even referent honorifics can be act-sensitive and are used strategically, which confirms the affinity of the inferential processes required in the interpretation of the interactional value of both honorifics and verbal strategies.

\section{Concluding remarks}


The observations on the Japanese language delineated in this paper can be summarised in the following three points: a re-evaluation of the notion of positive face and of speakercentred vs. hearer-centred behaviour (i.e. an emphasis on the multivalence of linguistic indexes), a revision of the claims regarding the culturally specific relevance of canons of wakimae (which has been equated to the notion of 'appropriateness'), and an indication of the limitations of past approaches to the characterization of wakimae.

\section{Positive and negative face needs}

Japanese data do not provide evidence that this language behaves any differently from those treated by Brown and Levinson, at least with respect to the criteria proposed by Ide and Matsumoto. Positive and negative constructs hold cognitive validity, if it can be shown that both verbal strategies and honorific forms work as they do because they rely on notions of territory, and notions of appreciation - more or less 'propositionally' depending on the device, but also irrespective of the device chosen. Unless one can prove that impositions on the hearer typically convey politeness (and the evidence discussed by Matsumoto does not), or that disregard for the hearer's attributes and wants does not cause disruptions to the relationship, then B\&L's rationale is not invalidated.

While one can intuitively identify negative and positive needs at which Japanese honorifics and other linguistic devices can be oriented, it has been consistently shown that it is not possible to categorize specific forms as invariably catering for one or the other aspect. The 'positively' or 'negatively' charged effects of a strategy are neutralized in the notion of 'what is expected', and in relation to this, local illocutionary goals can coincide or conflict with general social goals.

Many of B\&L's negative strategies are easily found in Japanese, but positive politeness strategies have received only fleeting attention (Held 1989; Scollon and Scollon 1983; Kasper 1990: 195), despite B\&L's rather provocative claim that the Japanese can be 
characterized as a 'negative politeness culture' (see Matsumoto 1988:408). However, if positive politeness has to do with the need to be appreciated, there is no reason why this appreciation cannot be generalized to any behaviour that ratifies the hearer's relevant attributes, i.e. the adherence to appropriate demeanour. This notion of positive politeness diverges from B\&L's only to the extent that they maintain that it is a redressive behaviour, and that it is typical of intimate relationships because it entails comity and intimacy. On the contrary, it has been shown that positive politeness is independent from potential threats (and it is also used for self-enhancement) and that it is critically necessary and routinely employed in non-intimate behaviour. Positive politeness is not necessarily linked to intimacy; in Japanese, comity appears more as solicitousness and with the social goal of promoting internal bounding (Ide 1989). Tactics that allow speakers to show appreciation for others and claim it for self are pervasively employed to construe stances which are instrumental to smooth interactional functioning, also in nonsymmetrical relationships (contrary to Scollon and Scollon 1983). The relevance view of politeness has de facto abandoned B\&L's restrictive interpretation of positive politeness and has focused on how we go about fabricating 'face respecting acts' (or rather 'supportive stances') in order to achieve behaviour that abides to canons of appropriateness. We can reformulate displays of positive politeness as (one of) the expected signal(s) of adherence to politic behaviour.

Also, we have seen that whether one's linguistic behaviour denotes a speaker-oriented or hearer-oriented strategy (or a prevailing concern for the speaker's or the hearer's face), cannot be told apart entirely. As Goffman (1972:81-2) put it, there is a great deal of overlapping between instances of deference and demeanour, even if it is convenient to separate them as analytical terms: giving or withholding deference is an expression of the fact that one is a well or badly demeaned individual, like willingness to conduct oneself 
with good behaviour is a way to show deference to others ${ }^{34}$. Honorifics and verbal strategies, as indexing devices, are transparent as to the speaker's evaluation of ego as well as they are of alter-subliminal as that may be. This is so whether speakers like or not, but these devices can, and are manipulated for the speaker's self-enhancement ${ }^{35}$. The speaker's own motives are clearly foregrounded in recent studies on politeness -the view of polite behaviour as egocentric behaviour in Watts (1992); Jary's (1998:2) viewing the attempts to protect the hearer's face as derivable from the speaker's wish to maintain and raise his own status; Meier's (1995:388) focus on Repair Work as an image-saving device for the speaker etc. The data discussed here are consistent with this perspective.

Meier (1995:385) warns that the characterization of positive politeness discussed above leads to strategies being ultimately undifferentiated, and that negative strategies are eventually subsumed under positive strategies. But this is inevitable and necessary. Negative face is an anti-social face. Rather, it is the need to be appreciated and supported -and the necessity to copy that need onto others- that drives individuals towards socialization, and as such it just has to be a pervasive, long-term concern. In linguistic

34 One should recall that his idea of deference is a very general form of 'regard', or "appreciation [that] is regularly conveyed to a recipient of this recipient, or of something of which this recipient is taken as symbol, extension or agent" (1967:56); it is not limited to respectful awe, but it includes affection and belonginess, trust, or capacity-esteem (1967:59); significantly, he sees deference as applying equally to symmetrical and asymmetrical relations. By means of increasing the speaker's social desirability (the payoff for the speaker's showing that the hearer's wants are his wants) it guarantees social cohesion.

35 Mao (1994:469) discusses this point and claims that according to Ide's analysis "a desire for approval can be inferred from the Japanese readiness to acknowledge and maintain each other's status differences", but contends that "such a desire remains secondary at best, as its fulfilment, if at all, is only seen as a welcome addition". The supportive argument that: "what initially motivates Japanese speakers to engage in this kind of face-work is the need to conform to social conventions and to express their desire to be part of the community", seems to me what the need of claiming a competent image/positive face for oneself is all about. The same point is discussed in Ji (2000:1060), and it is consistent with Meier's (1995:389) view of the function of Repair Work. 
terms, the fact that positive moves can incorporate negative moves only shows an inherent quality of a system based on strategic inferences. The distinction between these two vectors is perhaps less symmetrically elegant than in B\&L's model (we end up being forced to distinguish positive [comity] strategies from more general positive stances, which may include distancing strategies). This does represent an unacceptable taxonomic problem, but it does not prove that the identification of these two basic face needs is biased, nor disproves a claim of their (allegedly universal) heuristic value.

Clearly, cultures will show rather different orientations with respect to interaction norms, namely, whether face is given or gained by, for example, consistently providing close back-channelling rather than silently allowing longer turns, or using the interlocutor's surname in a business encounter rather than the first name, or again showing concern for consensual negotiation rather than adopting a directly persuasive style, and so on. Yet, any of these options requires an estimation of how close one can get to others (and others' domains of rights, dispositions etc), and how involved, appreciative etc. one needs to show one is in order to function competently and successfully in a specific social context. An individual's underlying ideology, attitudes, or disposition, even ideas of self are assessed via the orientations shown with regards to one's own and others' positive and negative aspects of face.

\section{Discernment and Volition}

Matsumoto's and Ide's work tried to show that the marking of rank has a stronger regulative power than individual volitional choices in the Japanese language, and that this is due to different constitutive traits of the Japanese self. I believe that the strongest conclusion that evidence proposed so far allows is that, at best, the wide range of devices dedicated to the marking of social identities makes their role simply more explicit. Jary's, Meier's, Watts' work suggests that notions of social role do have a crucial bearing on English as well, in that it is these macro-factors that constitute the background against 
which micro-factors can make a speaker's intentions (and local, contextual uses of honorific devices) interpretable at all. All their studies critically resort to notions of status differential or social distance to decipher a speaker's verbal behaviour, even with regards to unmarked states. In other words notions of status may constitute initial constrains, and where such assumptions are not shared or clear, the interlocutors must negotiate some. Sharing a set of assumptions on, or having negotiated what constitutes 'expected behaviour' (rights and duties of the participants), allows all resulting marked uses to be exploited to convey other relevant meanings. In this sense, the need of wakimae (discernment) is vital in communication regardless of the language.

Jary (1998:13) claims that appropriate behaviour, or what we have been used to call "polite verbal behaviour, is better seen as motivated by a desire to avoid (mis)communication." This occurs where speakers fail to provide enough evidence of the esteem in which they hold the addressee (in the terms of this paper, when he is unable to provide enough evidence of his concern for the hearers' positive face), or when his intentions are construed as manipulative (which could be construed as insufficient concern for the hearer's negative face). It is only in this sense that we can say that wakimae is a speaker's primary concern: as a preoccupation that the addressee does not infer from the speaker's utterances anything that may disrupt the relation on the longterm. A comparison of ways of uttering "today is saturday" in English and Japanese, far from justifying the corollary that the need to be appropriate is stronger in Japanese than in English, would only show that Japanese relies on the format of the copula -among other things- to make some speaker assumptions manifest, in a way that English cannot do.

Naturally, just revising taxonomies will not improve the discourse on politeness. Once one has recognised that both negative and positive moves are necessary to construe 'appropriate verbal behaviour', a more dynamic framework is needed to analyse what appropriateness is made of. One goal of this paper has been to challenge the notion that 
Japanese language behaves -in the mechanisms of interactional work - in a manner qualitatively different from English, or other languages. However, it has been pointed out that this universal notion of politeness as appropriateness yields two problematic issues for studies in the field.

The first is that while 'politic behaviour' is proposed as a universal of human communication, its content, as Watts $(1989,1992)$ cautions, is culturally determined. The explanatory power of this view is more modest than that proposed by B\&L (Janney and Arndt 1993), if we need to appeal to a priori knowledge of the relevant social norm in order to measure occurrences of honorifics or verbal strategies, and if concepts that describe such a norm must be defined anew in every new social context.

The second problem lies in the tendency to generalize 'social norms' excessively, overlooking the coexistence of different standards and ideologies (Janney and Arndt 1993, Okamoto 1997, Eelen 1999). A conceptualization of an individual that reasons only in terms of his personal needs (and can largely ignore social norms) is not less stereotypical than that of the Japanese irredeemably bound to a 'contextual' representation of self. The tendency to stereotyping cultures which even politeness research has been subject to is perpetually undermined by the objective difficulty of producing solid generalizations, despite evidence of patterning. Preferences can be identified in statistical terms (or with reference to 'dominant' metalinguistic ideologies: Okamoto 1997), yet an individual speaker's behaviour can only be assessed in specific contexts and situationally motivated performance (Okamoto 1997). Appropriateness cannot be thought of as a set of static, immutable precepts. But how do we go about characterizing what it is made of?

\section{Characterizing appropriateness}

A useful starting point could be the parameters that Ochs pointed out discussing "culturally distinct patterns in stance-act-activity-identity relations". These are at least 
some of the investigable components of cultural patterns. They organize and make recognisable actions, feelings and knowledge of members of a social group, all of which are thus seen as culturally mediated. Differences in these patterns, according to Ochs (1996:428), can be investigated in terms of "cultural expectations regarding a) the scope of stances and acts associated with particular activities and identities, b) the preferences for particular stances and acts within particular activities and for particular identities, and c) the extent of particular stance and act displays within particular activities and for particular identities".

As for Japanese, this view clearly urges us to abandon the postulate that we can rely on lists of honorific devices to identify polite 'acts' or even polite attitudes. Honorifics, perhaps most of all those structures that do not carry lexical meanings, lend themselves to take on situational connotates as much as verbal strategies. This has been shown by Minami (1987, see note 23) -among others- in his analysis of the cluster of meanings (stances) that an honorific can evoke.

Hence the adequate ground for research into the modalities of interaction should not be lists of forms that are conventionally associated with social marking, nor speech acts, but rather more general face threatening, and face respecting, stances. Sets of utterances like 1a/b/c ('today is saturday') cannot be considered as three different speech acts, but surely represent three different affective stances; as psychological 'postures' they cannot be classified straightforwardly as plain/polite/superpolite. The type of stance that they directly index is the perceived (psychologic) proximity between a speaker and a hearer. It is only by mediation through the interlocutors' cultural and ideological assumptions, and only in relation to previous verbal production and other available contextual evidence (Jary, 1998:8) that they can take on a particular meaning: that of status indicators such as intimacy or deference, that of affective disposition indicators such as aggression or coldness. This follows Ochs' view of the indexing of social meanings: with regards to the indexing of gender, she writes that (Ochs, 1993:146): "the relation between language and 
gender is not a simple straightforward mapping of linguistic form to social meaning of gender. Rather the relation of language to gender is constituted and mediated by the relation of language to stances, social acts, social activities and other social constructs". Because of this two-tier indexing process, and the potential multiplicity of social meanings that obtains from such social constructs, the indexing of polite intentions is unlikely to be a deterministic, straightforward enterprise even in linguistic systems like the Japanese (Okamoto 1997:810).

The need for an unbiased terminology for cross-cultural comparison is more urgent then ever, and the task of creating one as problematic as ever. Terms like 'deference', 'tact', 'superior', if not just 'politeness', clearly carry multiple connotations in different cultures, but most of all they are associated to clusters of different stances that need to be explicated. No universal syntax for 'affect' has been uncovered so far (Caffi and Janney 1994, Ochs 1996). Unless we acknowledge the miscellaneous composition of these concepts (and how their components are differentially relevant across cultures) crosscultural comparison is bound to be ill-informed (Wierzbicka 1985), and intra-culture research is bound to fall pray of the temptation to call upon reductionist, static and deterministic worldviews to characterize a linguistic style (Okamoto 1997).

Operationalizing concepts originated in one particular cultural framework onto another is not an adequate research agenda. If anything, the wealth of data available in a linguistic system like Japanese that encodes interactional modality in a relatively explicit fashion can be seen as a privileged source to set hypotheses on the processes whereby social meanings (and among these, the elusive notion of Linguistic Politeness) are pragmatically inferred from linguistic devices via the constitution of typical affective stances and other social constructs.

\section{References}

Agha, Asif, 1994. Honorification, Annual Review of Anthropology 23:277-302 
Bargiela, Francesca, in press, Face and Politeness. New (insights) for old (concepts), Journal of Pragmatics.

Brown, Penelope and Stephen Levinson, 1987. Politeness, Some Universals in Language Usage, Cambridge: Cambridge University Press

Caffi, Claudia \& Richard W. Janney, 1994. Toward a pragmatics of emotive communication, Journal of Pragmatics 22/3-4 (325-374)

Castelfranchi, Cristiano, 1988. Che figura. Emozioni e Immagine sociale ['How embarrassing'. Emotions and social image], Il Mulino, Bologna.

de Kadt, Elizabeth, 1998. 'The concept of face and its applicability to the Zulu language', in Journal of Pragmatics 29/2:173-191

Eelen, Gino, 1999. Politeness and ideology: A Critical review, Pragmatics 9/1:163-174

Fraser, Bruce, 1990. Perspectives on Politeness, Journal of Pragmatics 14/2:219-236

Fukada, Atsushi, Noriko Asato, 1997. The notion of Politeness revisited, manuscript of the paper read at the Eleventh Annual International Conference on Pragmatics and Language Learning, University of Illinois at Urbana-Champaign.

Geis, Michael L., 1995. Speech acts and conversational interaction - Toward a theory of conversational competence. Cambridge University Press, Cambridge

Glick, Douglas J 1996, A reappraisal of Brown andLevinson's Politeness: Some Universals of Language Use, eighteen years later. In: Semiotica 109-1/2:141-171

Goffman, Ervin 1972. On facework. In: Interaction Rituals - Essays on face-to-face interaction, Penguin: 5-47

Hamano, Shoko, 1993. Nonsubject honorification: a pragmatic analysis. In: Journal of Japanese Linguistics 15:83-111

Hymes, Dell (1986) Discourse: Scope without depth. International Journal of the Sociology of Language 57: 49-89.

Ide, Sachiko, 1982. Japanese Sociolinguistics. Politeness and Women's Language. In: Lingua 57:357-385

Ide, Sachiko, 1989. Formal forms and discernment: two neglected aspects of universals of linguistic politeness. In: Multilingua, 2/3:223-248

Held, Gudrun, 1989. On the role of maximization in verbal politeness. In: Multilingua 8(2) 167-206

Hill, Beverly, Ide Sachiko, Ikuta Shoko, Kawasaki Akiko and Ogino Tsunao, 1986. Universals of Linguistic Politeness. Quantitative Evidence from Japanese and American English. In: Journal of Pragmatics 10:347-471

Himeno, Motoko, 1991. Irai to Kan'yuu [Requests and Invitations], in Sekai no Nihongo Kyooiku 1, Saitamaken Urawashi, Doo Sentaa:69-81 
Ikeda, Rieko. 1993. Shazai no taishokenkyuu-Nichibei taishoukenkyuu -face to iu shiten kara [Contrastive study of Apologies - Contrastive study of Japanese and American - observations from the viewpoint of politeness] Nihongogaku 12:13-21

Ikuta, Shoko. 1983, Speech level shift and conversational strategy in Japanese discourse. In: Language Sciences 5/1:37-53

Janney, Richard W. and Horst Arndt, 1993. Universality and relativity in cross-cultural politeness research: a historical perspective. In: Multilingua 12: 7-34

Jary, Mark, 1998. Relevance Theory and the communication of politeness. In: Journal of Pragmatics 30:1-19

Ji Shaojun, 2000. 'Face' and polite verbal behaviours in Chinese culture. In: Journal of Pragmatics 32:1059-1062

Kamio Akio, 1994. The theory of territory of information: the case of Japanese. In: Journal of Pragmatics 21/1:67-100

Kamio, Akio, 1997. [Japanese original: 1990], Territory of Information, John Benjamin Publishing Company, Amsterdam

Kabaya, Hiroshi, Yoshikazu Kawaguchi and Megumi Sakamoto, 1998. Keigo Hyoogen [Polite Expressions], Taishuukan Shoten, Tokyo

Kasper, Gabriele, 1990. Linguistic Politeness. In: Journal of Pragmatics 14 (2):193-218

Kerbrat- Orecchioni, Catherine, 1997. The study of talk in interaction. In: Pragmatics $7 / 1: 1-21$

Kikuchi, Yasuo, 1996. Keigo sainyuumon [New Introduction to Politeness], Maruzen Library, Tokyo

Kikuchi, Yasuo, 1997. Keigo [Japanese Politeness], Koodansha Gakujutsu Bunko, Tokyo

Koizumi, Tamotsu, 1990, Gengai no gengogaku [Implicational linguistics], Sanseidoo, Tokyo

Kokuritsu Kokugo Kenkyuujo ed., 1990, 1992. Keigo kyooiku no kihon mondai [Fundamental issues in the teaching of politeness], vol I and II, Okurasho Insatsukyoku, Tokyo

Kumai, Hiroko, 1988. Gendai Nihongo ni okeru 'Keigo Yuuhatsu' ni tuite [On 'induced politeness' in contemporary Japanese]. In: Kokugogaku 152:31-46

Lakoff, R., 1973. The Logic of Politeness: Or minding your P's and Q's, In: C.Corum, T. Cedric smith-Stark and A. Weiser, eds., Papers from the ninth regional meeting of the Chicago Linguistic Society, Chicago IL: Chicago Linguistic Society:292-305

Laver, John, 1984. Communicative functions of phatic communion, in A. Kendon, R. M. Harris and M.R.Key (eds), The organization in Face-to-Face interactions, TheHague: Mouton. 
Leech, Geoffrey, 1983. Principles of Pragmatics, Longman Linguistics Library, London and New York.

Levinson, Stephen, 1983. Pragmatics, Cambridge, Cambridge University Press

Martin Samuel E., 1988 [1975]. A reference Grammar of Japanese, Tuttle Language Library, Tokyo.

Mao, LuMing Robert, 1994. Beyond politeness theory: 'Face' revisited and renewed. In: Journal of Pragmatics 21:451-486

Martin, Samuel E., 1975 [Japanese edition 1988]. A Reference Grammar of Japanese, Tuttle Language Library, Tokyo.

Matsumoto, Yoshiko, 1988. Reexaminations of the universality of face. In: Journal of Pragmatics 12(4): 403-426

Matsumoto, Yoshiko, 1989. Politeness and conversational universals- Observations from Japanese. In: Multilingua 8- 2/3:207-221

Matsumoto, Yoshiko, 1993. Linguistic Politeness and Cultural Style: Observations from Japanese. In Patricia M. Clancy ed., 1993, Japanese and Korean Linguistics vol. 2, 55-67, Center for the study of Language and Information, Stanford University

Matsumoto, Yoshiko 1997. The rise and fall of Japanese nonsubject honorifics: the case of 'o-Verb-suru'. In: Journal of Pragmatics 28:719-740

Maynard, Senko, 1992. Discourse Modality: Subjectivity, Emotion and voice in the Japanese Language, John Benjamins Amsterdam

Meier, Ardith J., 1995. Passages of politeness. In: Journal of Pragmatics 24:381-392

Minami, Fujio, 1974. Gendai keigo no imi koozoo [The structure of contemporary Japanese Politeness]. In Kokugogaku 96:85

Minami Fujio 1987. Keigo [Linguistic Politeness] Tokyo: Iwanami Shoten

Mimaki, Yoko, 1997, Danwa ni okeru FTA hoshoo sutoratejii -Taiguu reberu shifuto o chuushin ni [FTA redressive strategies in conversation - On speech level shift]. In: Osaka Daigaku Ryuugakusei Sentaa Kenkyuu Ronshuu, first issue, Osaka University, Osaka: 59-78

Noda, Hisashi, 1998. Teineisa kara mita Bunsho-Danwa no Koozoo, [The structure of texts and conversation from the politeness point of view]. In: Kokugogaku 194:114

Nwoye, Onuigbo G, 1992. Linguistic Politeness and socio-cultural variations of the notion of face. In: Journal of Pragmatics 18:309-328

Ochs, Elinor, 1993. Indexing Gender. In: B.D. Miller, ed., Sex and Gender Hierarchies, Cambridge University Press, Cambridge:146-169 
Ochs, Elinor, 1996. Linguistic resources for socializing humanity. In Gumperz, John J and S. Levinson, eds., Rethinking Linguistic Relativity, Cambridge University Press:407-437

Ohso, Mieko, 1983. Invitation, Polite order, Personal Request and Begging. In: Papers in Japanese Linguistics 9, Kuroshio Shuppan:Tokyo: 141-150

Ohso Mieko, 1987. Ashita shiken o o-uke shimasu [I shall take the exam tomorrow], Nihongogaku 2:131-134

Okamoto, Shigeko, 1997. Social context, linguistic ideology, and indexical expressions in Japanese. In: Journal of Pragmatics 28:795-817

Okamoto, Shigeko, 1999. Situated politeness: manipulating honorific and non-honorific expressions in Japanese conversations. In: Pragmatics 9/1:51-74

Ooishi, Hatsutaroo, 1986 Keigo [Politeness], Chikuma Shoboo, Tokyo

Pizziconi Barbara 1997 Cortesia Linguistica e immagine sociale - Osservazioni sugli universali linguistici e la lingua giapponese ['Linguistic Politeness and Social Image: Observations on the Linguistic Universals and the Japanese Language'], unpublished $\mathrm{PhD}$, Istituto Universitario Orientale, Naples University, Department of Asian Studies.

Sasagawa, Yooko, 1994. Ibunka ni mirareru 'Teineisa no ru-ru' no hikaku, [Crosscultural comparison of 'rules of politeness']. In: Ibunka Kyouiku 8 (Tokushu: Ibunka rikai to gengo kyouiku), Ibunka Kyouiku Gakkai: 44-37

Schmidt, Richard W., 1980. Review of E. Goody, ed.: Questions and Politeness: Strategies in Social Interaction. In: RELC Journal 11/2:101-114

Scollon, Ron and Suzanne B.K. Scollon, 1983. Face in interethnic communication. In: Richards, Jack and Richard W. Schmidt, Language and Communication, Longman, New York:156-190

Shibata, Takeshi ed., 1976. Gendai Nihongo [Contemporary Japanese], Asahi Shinbun, Tokyo

Suzuki, Mutsumi, 1989. Kikite no Shiteki Ryooiki to Teinei Hyoogen [The Hearer's private territory and polite expressions], Nihongogaku 8:58-67 Tokyo:Meiji shoin

Thomas, Jenny, 1995. Meaning in Interaction: an Introduction to Pragmatics, London, Longman

Toyama, Eiji, 1977. Keigo no hensen [Metamorphoses of Polite Expressions]. In Keigo, Iwanami kooza Nihongo 4: 152, Iwanami Shoten, Tokyo

Tsujimura, Toshiki, 1992. Keigo ronkoo [Studies on Politeness], Meiji shoin, Tokyo

Usami, Mayumi, 1995. Danwa reberu kara mita Keigo shiyou - Supi-chi reberu shifuto seiki no jouken to kinou - [Conditions for speech-level shift occurrence in 
Japanese discourse]. In: Gakuen 662, Showa Joshi Daigaku Kindai Bunka Kenkyujo:27-42

Usami, Mayumi, 1997. Poraitonesu riron no tenkai: Disukousu Poraitonesu to iu toraekata [Developments of the Politeness Theory: its interpretation as Discourse Politeness]. In: Nihon kenkyuu Kyoiku Nenpou, Tokyo University of Foreign Studies: 145-159

Watts, Richard J, 1989. Relevance and relational work: linguistic politeness and politic behaviour. In: Multilingua 8 - 2/3: 131-166

Watts, Richard J, 1992. Linguistic Politeness and politic verbal behaviour: Reconsidering claims for universality. In: Watts, R.J., S. Ide and K. Ehlich eds., Politeness in Language, 43-69, Berlin, Mouton

Watts, Richard J., Sachiko Ide and Konrad Ehlich, 1992. Introduction. In: Watts, R.J., S. Ide and K. Ehlich eds., Politeness in Language, 1-17, Berlin, Mouton

Wierzbicka, Anna, 1985. Different cultures, different languages, different speech acts. In: Journal of Pragmatics 9: 145-17

Wolfson, Nessa, 1989. Perspectives: Sociolinguistics and TESOL, Cambridge, MA:Newbury House 